\title{
PANORAMA DA RECEPÇÃO CRÍTICA DE HIROSHIMA MON AMOUR NO BRASIL
}

http://dx.doi.org/10.11606/issn.2237-1184.v0i31p100-112

Alessandra Brum ${ }^{\mathrm{I}}$

\section{RESUMO}

Na década de 1960, havia no Brasil uma intensa atividade em torno da crítica de cinema que era exercida em quase todos os jornais e revistas com grande visibilidade entre seus leitores. A exibição de Hiroshima mon amour (1959), primeiro longa-metragem de Alain Resnais, foi um marco não só pelas suas renovações estéticas, mas também pelo grande impacto causado entre os críticos, motivando um caloroso debate refletido nos inúmeros artigos publicados sobre o filme. Este artigo tem por objetivo traçar um panorama da recepção crítica de Hiroshima mon amour no Brasil.

\section{ABSTRACT}

In the 1960s, there was an intense activity in Brazil around film criticism that was practiced in almost all newspapers and magazines with great visibility among its readers. The exhibition of Hiroshima mon amour (1959), Alain Resnais' first feature film, was a milestone not only for its aesthetic renewals but also for the great impact caused among critics, motivating a warm debate reflected in the numerous articles published about the film. This article aims to provide an overview of the critical reception of Hiroshima mon amour in Brazil.

\section{PALAVRAS-CHAVE:}

Crítica de cinema;

Alain Resnais;

Hiroshima mon amour.

\section{KEYWORDS}

Film criticism;

Alain Resnais;

Hiroshima mon amour.

\footnotetext{
I Universidade Federal de Juiz de Fora, Juiz de Fora, Minas Gerais, Brasil.
} 
ste artigo tem por objetivo traçar um panorama da fortuna crítica produzida no Brasil sobre o filme Hiroshima mon amour (1959, $91 \mathrm{~min}$ ), de Alain Resnais. Para tal nos utilizamos de um amplo material publicado na grande imprensa e em revistas especializadas do início dos anos 1960, quando o filme foi exibido no Brasil. Resultado de uma pesquisa mais ampla, ${ }^{1}$ aqui o leitor terá uma compilação das principais ideias que nortearam e inquietaram os principais críticos de cinema em atividade da época.

A polêmica em torno de Hiroshima mon amour começou quando o filme foi exibido fora da competição oficial do Festival de Cannes por questões políticas. ${ }^{2}$ Mas foi depois de sua exibição que se acentuou o desconforto em relação ao filme. Até aquele momento nenhum filme havia ousado tanto na forma de empregar os elementos da linguagem cinematográfica, dividindo as opiniões do júri do Festival e se tornando o mais discutido filme na imprensa e nas revistas especializadas.

A Literatura, diziam alguns críticos franceses, ${ }^{3}$ havia tomado um lugar nunca antes ocupado no cinema e, a responsabilidade por isto recaía também sobre a escritora Marguerite Duras que escreveu o "roteiro" do filme. ${ }^{4} \mathrm{O}$ desconforto dos críticos de cinema diante do filme foi latente, $\mathrm{O}$ que ocasionou uma nova postura da crítica, estabelecendo novas bases para a análise que realizavam. Na revista Cahiers du Cinéma (n. 97, jul. 1959) foi realizada uma mesa redonda ${ }^{5}$ para se discutir esse evento que foi a exibição de Hiroshima mon amour. Neste debate, Éric Rohmer afirma que Alain Resnais "é o primeiro cineasta moderno do cinema falado" (p. 41).

Essa inquietação provocada por Hiroshima mon amour atravessou o Atlântico. Antes mesmo de sua exibição no Brasil, o filme já foi assunto da crítica brasileira. Antonio Moniz Vianna6 (2004, p. 192) comenta esse momento que antecipa a chegada do filme ao Brasil:

\footnotetext{
${ }^{1}$ Este artigo resulta de uma pesquisa maior desenvolvida para a minha tese de doutorado defendida junto ao Programa de pós-graduação em Multimeios da Unicamp e publicada em livro sob o título Hiroshima mon amour e a recepção da crítica no Brasil (2017), com o apoio da FAPESP.

2 O Festival de Cannes decidiu exibir o filme fora da competição oficial para não desagradar aos Estados Unidos da América.

${ }^{3}$ Sobre isso ver o tópico "Nascimento de um clássico". In: BRUM, 2017, p. 50-9.

${ }^{4}$ Alain Resnais deu total liberdade para a escritora Marguerite Duras para que ela desenvolvesse a história sem as amarras do formato de um roteiro, podendo se expressar através da literatura. 5 A mesa-redonda foi intitulada Hiroshima, notre amour e contou com a participação de Jean Domarchi, Jacques Doniol-Valcroze, Jean-Luc Godard, Pierre Kast, Jacques Rivette e Éric Rohmer. Essa foi a segunda mesa redonda realizada pela revista. A primeira aconteceu em 1957 e teve por objetivo discutir a crise do cinema francês.

${ }^{6}$ Antonio Moniz Vianna era crítico de cinema do Correio da Manhã, atividade que exercia desde 1946. Apaixonado pelo cinema Hollywoodiano, Moniz era muito prestigiado e respeitado por seus pares.
} 
A reação crítica imediata ante a Hiroshima mon amour, na França, foi de estupefação ou de perplexidade, mas ao se organizar em análise, não era tão favorável quanto se faz crer por aqui, onde o filme já era elogiado antes mesmo de ser conhecido.

Depois de sua primeira exibição no Brasil e obedecendo a critérios comerciais da época, Hiroshima mon amour entra em circuito comercial em 30 de agosto de 1960, com classificação indicativa de 18 anos. Diante do tamanho do nosso território, o filme de Alain Resnais teve estreias programadas durante o ano de 1961 e 1962. Contabilizamos em nossa pesquisa 52 artigos, ${ }^{7}$ entre jornais e revistas, destinados exclusivamente ao filme. O número expressivo de artigos é uma exceção dentro do trabalho da crítica da época, uma vez que poucos filmes mereceram tamanha atenção.

Neste período, a atividade em torno da crítica de cinema era exercida em quase todos os jornais e revistas do país. O exercício da crítica rivalizava, em grau de importância, com o filme em si. Uma das consequências da exibição do filme Hiroshima mon amour foi a percepção da necessidade de uma revisão do trabalho da crítica assumida pelos próprios críticos. Temos, como afirmou Antonio Moniz Vianna, dois partidos formados, uns contra e outros a favor da obra de Alain Resnais. O crítico e ensaísta Walter da Silveira ${ }^{8}$ observa que há uma dificuldade por parte da crítica ao analisar Hiroshima mon amour de se libertar de uma teoria que se originou no cinema silencioso. Por outro lado, há por boa parte da nova geração de críticos uma adesão à forma empregada por Alain Resnais. Aqui procuramos destacar as principais ideias que nortearam o pensamento da crítica de cinema no Brasil em torno do filme de Alain Resnais.

\section{A exibição de Hiroshima mon amour no Brasil.}

A primeira exibição de Hiroshima mon amour no Brasil aconteceu em 24 de janeiro de 1960 às 10h30 no Cine Art-Palácio na cidade de Belo Horizonte, como parte integrante da programação da II Jornada dos Cineclubes Brasileiros, co-patrocinada pelo Centro de Estudos Cinematográficos de Minas Gerais (CECMG). ${ }^{9}$

\footnotetext{
7 Todos os artigos foram catalogados e discutidos em BRUM, 2017.

${ }^{8}$ Walter da Silveira foi um dos fundadores do Clube de Cinema da Bahia, de onde saíram nomes como Glauber Rocha e Roberto Pires.

9 A cópia de exibição era com legendas em espanhol e, segundo o crítico José Haroldo Pereira, essa foi a primeira exibição na América Latina.
} 
José Haroldo Pereira, ${ }^{10}$ que mais tarde escreve um artigo sobre o filme na segunda fase da Revista de Cinema, descreve esse momento logo após a primeira sessão no Brasil.

Foi exibido domingo, em um auditório na Praça Sete e foi aquele impacto. Acabou o filme e ficou todo mundo estatelado, deslumbrado, sem entender muito o que estava acontecendo. Como um filme poderia ser tão ousado a ponto de fundir cinema com literatura? (BRUM, 2008, p. 71)

A partir dessa primeira exibição, restrita ainda a um público especializado de críticos, cineclubistas e apaixonados pela arte cinematográfica, o filme ganha repercussão e começam a aparecer as primeiras críticas. A primeira apreciação que encontramos sobre Hiroshima mon amour foi a do crítico de cinema Maurício Gomes Leite. ${ }^{11}$ Em sua coluna no Diário da Tarde (MG), do dia 26 de janeiro de 1960, ele convoca toda a crítica mineira, inclusive os críticos ausentes da atividade diária, a se debruçar em estudo dessa "obra inavaliável".

Neste mesmo ano em que ocorre a exibição de Hiroshima Mon amour no Brasil, acontece a primeira Convenção Nacional da Crítica Cinematográfica, organizada pela Fundação Cinemateca Brasileira e promovida pela Comissão Estadual de Cinema do Governo do Estado de São Paulo, entre os dias 12 e 15 de novembro de 1960, na cidade de São Paulo. Nessa Primeira Convenção, estava reunida praticamente toda a crítica brasileira em atividade na época, críticos de diferentes gerações e de vários estados brasileiros. Paulo Emílio Salles Gomes 12 apresentou duas comunicações no evento: "Uma situação colonial?"13 e "A ideologia da crítica brasileira e o problema do diálogo cinematográfico". Nesta segunda comunicação, Paulo Emílio defende a ideia de um cinema pautado pelo diálogo. Para ele, "nas condições brasileiras atuais, a ideologia cinematográfica mais útil e, portanto, 'verdadeira' seria a que definisse o cinema como uma fala literária e dramática envolvida por imagens" (GOMES, 1986, p. 333-4). Essa afirmação gerou um mal-estar entre os participantes que o acusaram de estar sob influência de Hiroshima mon amour. $\mathrm{O}$ jornal $O$ Metropolitano, ${ }^{14}$ que realizou a cobertura jornalística do evento, reproduz

\footnotetext{
${ }^{10}$ Jovem crítico de cinema, formado pelos quadros do Centro de Estudos Cinematográficos de Minas Gerais, exercia crítica diária no Jornal Folha de Minas.

${ }_{11}$ Maurício Gomes Leite era considerado um dos nomes mais importantes da nova geração de críticos mineiros.

12 Paulo Emílio Salles Gomes, dispensa grandes apresentações, foi um dos mais respeitados e influentes crítico e ensaísta de cinema do Brasil. Escrevia para o Suplemento Literário d'O Estado de São Paulo e foi fundador da Cinemateca Brasileira.

13 "Uma Situação Colonial?" foi posteriormente publicada no Suplemento Literário d'O Estado de São Paulo em 19 nov. 1960.

${ }^{14}$ O Metropolitano era um jornal da União Metropolitana dos Estudantes e era encartado junto ao Diário de Notícias do Rio de Janeiro. Foi considerado um dos núcleos de gestação do Cinema Novo.
} 
nas páginas do jornal essa tese de Paulo Emílio Salles Gomes. Diz a matéria:

O diálogo, não resta a menor dúvida, é o ponto crucial do nosso cinema. [...] Mas, perguntaríamos, seria Paulo Emílio favorável também à dublagem de fitas estrangeiras? Ou estaria ele a sofrer ainda o prazer estético que tanto divulgou, oriundo de Hiroshima, mon amour, cujo texto levou-o a considerar a fita o primeiro passo na conquista do cinema lírico? (PERDIGÃO, 1960)

Como podemos observar foi impossível ficar indiferente ao filme de Alain Resnais que passou a ocupar espaço nos debates da Convenção, se tornando ponto de referência para uma compreensão do cinema como arte.

\section{Preparando o espectador ou tentando compreender Hiroshima mon amour.}

Há por parte da crítica brasileira uma preocupação em preparar o leitor / espectador para as novidades que o novo filme de Alain Resnais trazia às telas. $\mathrm{O}$ crítico Cláudio Mello e Souza,15 em seu artigo intitulado "Hiroshima e o público" (MELLO E SOUZA, 1960), trabalha com a ideia de que Hiroshima mon amour é muito difícil para o espectador por representar "o rompimento total com a convenção". Esta era uma hipótese que foi tema de alguns comentários críticos e de suposições de que o filme teria sido um grande fracasso de bilheteria. ${ }^{16}$

Mas, não era apenas para o espectador comum que Hiroshima mon amour era um filme difícil e incomum. Ely Azeredo, ${ }^{17}$ em sua coluna na Tribuna da Imprensa, comenta a posição da crítica.

Para a crítica cinematográfica digna desse nome, o filme que veremos amanhã, "Hiroshima, meu amor", inquieta por mais de uma razão. A inquietude começa, para os críticos diários, ante a complexidade de espírito e forma, que parece exigir o tempo, a liberdade de espaço e as possibilidades de aproximação paulatina e pesquisa dos ensaístas.

Mais de um crítico já se referiu com um certo mal-estar ao filme de Alain Resnais, afirmando que é "tão difícil gostar quanto não gostar de Hiroshima". Após comentários entusiásticos,

\footnotetext{
15 Crítico diário do Diário Carioca.

16 Não há como sabermos o resultado da bilheteria do filme no Brasil, mas Glauber Rocha (1961), em seu artigo "O Processo Cinema", diz que o supervisor da França Filmes no Brasil afirmou que "a bilheteria foi fantástica". Paulo Emílio Salles Gomes (1960), em seu artigo "A pele e a paz", tem como hipótese de que o filme alcançou uma boa bilheteria pelo fato do espectador precisar assistir várias vezes ao filme para poder compreendê-lo.

17 Ely Azeredo tinha uma coluna diária no jornal Tribuna da Imprensa e posteriormente exerceu a crítica de cinema do Jornal do Brasil.
} 
impressionados, alguns encontram necessidade de assegurar ao leitor que não gostaram tanto assim de "Hiroshima", e que, se deram essa impressão de total adesão, não se expressaram da maneira mais adequada. (AZEREDO, 1960, p. 9)

A necessidade por parte dos críticos de cinema de um maior aprofundamento frente às questões provocadas pelo filme fez com que eles resolvessem o problema escrevendo séries de artigos a fim de superar as limitações impostas pelo espaço destinado a eles nas páginas dos jornais. Paulo Emílio Salles Gomes escreveu cinco artigos no Suplemento Literário d' O Estado de S. Paulo; Walter da Silveira, quatro artigos no Diário de Notícias de Salvador; José Haroldo Pereira, no Folha de Minas cinco e José Sanz, ${ }^{18}$ no Jornal do Commercio, seis artigos, só para citar alguns exemplos.

O que explica e provoca tamanha imersão no filme é a ideia de um cinema moderno. Hiroshima mon amour é um filme que transgride as regras de continuidade, de necessidade dramática e que não se acomoda dentro de uma estrutura narrativa fartamente utilizada pelo cinema clássico Hollywoodiano. Os procedimentos narrativos empregados por Alain Resnais articulam o tempo presente com o tempo passado respeitando o fluxo do pensamento da personagem de Emmanuelle Riva. Os flashbacks, por exemplo, não são um simples retorno ao passado que nos ajuda a entender a ação do presente, funcionam como elemento de continuidade e interação entre as ações do passado com as do presente. Maurício Gomes Leite, que escreveu o primeiro artigo sobre o filme no Brasil, diz:

Hiroshima mon amour é uma "extraordinária tentativa de Alain Resnais em registrar na tela a descrição interior de uma experiência amorosa, é também o coroamento dos vários ensaios feitos rumo à criação de um cinema subjetivo, de um cinema onde o personagem - ou a mente do personagem - é o centro de todos os acontecimentos.

[...] Por ora, deve ser notado, sobretudo que Alain Resnais, com Hiroshima mon amour, eleva o diálogo, o monólogo e a narração à mais pura categoria cinematográfica, dando pela primeira vez dimensões surpreendentemente avançadas ao elemento sonoro. [...] Veremos depois, então, se Hiroshima mon amour representará para a nossa época o que Cidadão Kane foi para a década de quarenta.

Este primeiro artigo de Maurício Gomes Leite dará o tom das análises posteriores, apontando para algumas questões que serão discutidas por vários críticos brasileiros: a relação cinema versus literatura;

\footnotetext{
${ }^{18}$ José Sanz tinha uma coluna diária no Jornal do Commercio. Ele foi o responsável pela tradução das legendas de Hiroshima mon amour para o português.
} 
a memória como condutora da narrativa cinematográfica; e a ideia de filme-ruptura. ${ }^{19}$

A relação cinema versus literatura foi tema de uma série de artigos de Walter da Silveira que conduz sua análise na tentativa de demonstrar que "essa fita polêmica alarga, por uma compreensão mais futura do cinema, sua posição no quadro das artes" (SILVEIRA, 2006, p. 216). Embasado a partir de textos sobre a obra de Alain Resnais e de depoimentos do cineasta às revistas Téléciné e Tiempo Del Cine, Walter da Silveira, ao relatar o processo de criação do filme em sua concepção embrionária (que inclui o fato de a escritora Marguerite Duras não escrever o texto em formato tradicional de um roteiro cinematográfico), ressalta o valor singular do trabalho do diretor que transpõe para o cinema uma obra literária. Diz Silveira: “A suposta descaracterização do cinema pela fala é um problema que já devia estar ultrapassado, mas que Alain Resnais teve de enfrentar em Hiroshima, mon amour com a audácia de um revolucionário" (SILVEIRA, 2006, p. 217). Walter da Silveira acredita que os críticos e os teóricos do cinema, de uma maneira geral, não estão sintonizados com o advento do cinema falado; e argumenta que a teoria cinematográfica tem suas bases sedimentadas no cinema silencioso, o que impede uma compreensão mais adequada do novo filme de Resnais.

O uso excessivo da palavra, atribuído a Marguerite Duras, foi destacado em diversas análises. Os críticos Maurício Gomes Leite, José Lino Grünewald20, José Sanz, Glauber Rocha ${ }^{21}$ e Walter da Silveira consideraram que a palavra, fonte da literatura, era uma aliada do cinema. A condução das narrativas cinematográficas pela memória do personagem de Emmanuelle Riva levou as análises ao estabelecimento de relações com a literatura moderna, trazendo nomes como os dos escritores Marcel Proust, Willian Faulkner, James Joyce e John dos Passos.

Já Antonio Moniz Vianna e Pedro Lima22 encontraram na força da palavra o maior defeito do filme de Resnais. Para esses críticos, o

\footnotetext{
${ }^{19}$ Quando Maurício Gomes Leite escreveu esse artigo em janeiro de 1960, ele já tinha tido acesso às revistas francesas, sobretudo a Cahiers du Cinema (Juillet, 1959), já que em determinado momento de sua análise cita uma observação que Jacques Rivette fez na mesa redonda promovida pela revista francesa sobre Hiroshima mon amour. Essa mesa redonda foi amplamente difundida entre os críticos brasileiros, chegando a ter parte de seu conteúdo traduzido e publicado no Suplemento Dominical do Jornal do Brasil de 10 de setembro de 1960.

${ }^{20}$ José Lino Grünewald era poeta e tradutor, contribui como crítico para o Correio da Manhã, o Jornal do Brasil e Jornal de Letras. Grünewald se diferencia da sua geração por introduzir em suas análises autores da filosofia, como Maurice Merleau-Ponty, Ernst Cassirer e Walter Benjamin, só para citar alguns exemplos.

${ }^{21} \mathrm{O}$ cineasta Glauber Rocha não necessita de grandes apresentações. Neste período da exibição de Hiroshima mon amour no Brasil, Glauber realizava seu primeiro longa-metragem Barravento (1961, 81min) e contribuía de forma esporádica para o Diário de Notícias da Bahia como crítico de cinema, bem como em outros jornais do país.

22 Pedro Lima é um dos críticos mais antigos em atividade na década de 1960. Sua vida inteira foi dedicada ao cinema. Atuou nas revistas Selecta e Cinearte e depois colaborou para O Jornal, Diário da Noite e O Cruzeiro.
} 
excesso de literatura predomina sobre a imagem, deixando em segundo plano a essência do cinema, que é o visual. Eles acreditavam que o filme de Resnais não seria compreensível ao espectador sem a palavra e isto era inconcebível. $\mathrm{O}$ fato de Alain Resnais imprimir ao som e à imagem o mesmo peso é o que os incomodou. Walter da Silveira, parece certeiro ao afirmar que os críticos não estavam em sintonia com o advento do cinema falado, pelo menos os da antiga geração.

Apesar de parte da crítica brasileira buscar referências na literatura, não encontramos nas análises referência à literatura de Marguerite Duras. Observamos um total desconhecimento da obra e do estilo da escritora no Brasil. Mesmo Paulo Emílio Salles Gomes, que teve parte de sua formação intelectual constituída na França, confessa não conhecer "nenhum dos romances de Marguerite Duras" (GOMES, 1960). A relação de Alain Resnais com escritores do Nouveau Roman na criação de seus filmes é motivo de comentários apenas de Ely Azeredo, mas mesmo assim ele não relaciona esse movimento literário com a literatura produzida por Marguerite Duras. Seria de se esperar que houvesse por parte da crítica algum comentário nesse sentido, posto que a "dialética" memória e esquecimento foi tema recorrente entre os críticos brasileiros, e no Brasil, o Nouveau Roman já era conhecido pelos críticos literários, uma vez que encontramos textos referentes ao tema no Suplemento Literário d' O Estado de S. Paulo já em abril de 1960.23 Sabemos que essa ligação de Marguerite Duras com o Nouveau Roman é sempre muito discutida, não apenas porque a escritora recusou se enquadrar em qualquer escola literária, mas também por ela possuir um texto muito singular, de intensa personalidade. Sendo parte integrante ou não desse movimento literário, o que nos interessa é que Duras faz da subjetividade humana o elemento central de sua narrativa, ponto que certamente pesou na escolha do diretor Alain Resnais por seu nome na escrita do roteiro e dos diálogos, e é no mínimo curioso que os críticos brasileiros ignorassem a literatura dela e ela como roteirista do filme. Essa lacuna nas análises talvez possa ser explicada, por um lado, pelo fato de se tratar de outra área de conhecimento e, por outro, por ser uma associação inusitada: forma literária com forma cinematográfica.

Outro ponto que gostaríamos de salientar é o fato de que quase a totalidade dos críticos em atividade na década de 1960 serem do sexo masculino. Na primeira convenção Nacional da crítica de cinema, apenas três mulheres compareceram ao evento. ${ }^{24}$ Não encontrei, em minhas pesquisas, nenhuma crítica sobre Hiroshima mon amour realizada por uma

\footnotetext{
${ }^{23}$ Refiro-me ao texto: PERRONE-MOISÉS, Leyla. Aspectos do "nouveau roman". O Estado de São Paulo, Suplemento Literário. São Paulo, 2 abr. 1960.

24 São elas: Dayse Ferreira, Zenaide Andréa e Ilka Brunilde Laurito.
} 
mulher, apenas um comentário crítico de Tati de Moraes ${ }^{25}$ no material promocional do filme distribuído pela França-Filmes do Brasil. Diz Tati de Moraes:

\begin{abstract}
O que fascina também em Hiroshima... é a sua feminilidade. Escrito por uma mulher (como não poderia deixar de ser) a sua essência é a frustração de um amor feminino que julga trair quando começa a esquecer. $\mathrm{O}$ esquecimento começa pelos olhos... Do ponto de vista pacifista, o filme ainda é feminino no seu ódio contra os tabus que a guerra cria, na sua revolta contra o sacrifício absurdo da infância e da juventude.
\end{abstract}

Hiroshima mon amour é um filme feminino não apenas por ter sido escrito por uma mulher, no caso Marguerite Duras, mas por ter como protagonista e condutora incondicional da narrativa uma mulher. Portanto, a ausência de críticas escritas por mulheres é uma grande lacuna no trabalho da crítica de cinema em relação ao filme de Alain Resnais.

Ainda nessa relação entre cinema e literatura, os críticos brasileiros encontram no dueto "filme-poema" uma definição para Hiroshima Mon Amour. Esse conceito pode estar presente no diálogo, como defendeu José Sanz ao afirmar que "a voz que se ouve em Hiroshima, a de Emmanuelle Riva, traduz em palavras as imagens existentes em sua memória, dandolhes um sentido que transcende a imagem" (SANZ, 1960). Filme-poema pode estar também na forma do filme, como afirmaram Maurício Gomes Leite e José Haroldo Pereira. Para Pereira (1960), por exemplo, "Hiroshima mon amour é virtualmente uma obra-prima de romance". Os empregos formais adotados pelo cineasta Alain Resnais provocam reflexões no sentido de ser o filme "a maior negação do mito cinema-espetáculo", uma vez que Resnais ignora por completo o espectador. Para José Haroldo Pereira é justamente esse caminho adotado pelo cineasta que transforma a realidade num universo aberto, pois o espectador é "livre diante de um filme, já que este ao invés de lhe propor uma intriga, propõe-lhe refletir" e conclui que o filme é uma "forma sublime de poema".

Outro ponto que motivou os debates em torno do filme de Resnais foi a memória como condutora da narrativa cinematográfica. A expressão da subjetividade, do tempo da memória, recursos muito mais empregados pela literatura do que pelo cinema, são discutidos no sentido de se pensar os recursos cinematográficos. Para José Haroldo Pereira, por exemplo, Alain Resnais inaugura no cinema um novo plano na narrativa, o plano-memória que se apresenta como expressão da memória do personagem. Com essa nova visão estética, Resnais introduz um novo tipo de montagem que atende "a lógica do pensamento humano".

25 Tati de Moraes colabora na seção de cultura do jornal Última Hora, no entanto, não encontramos nenhuma análise dela no jornal da época. Diante disso, temos como hipótese de que ela tenha sido convidada a escrever sobre o Hiroshima mon amour pela França-Filmes. 
A montagem realizada por Resnais em Hiroshima mon amour foi algumas vezes associada ao conceito de "montagem de atrações" de Eisenstein, ou seja, a junção de planos conflitantes com objetivo de produzir choques emocionais no espectador, sendo que em Hiroshima mon amour, isso é ampliado, como afirmou José Lino Grünewald (2001, p. 54). Já José Haroldo não nega a influência de Eisenstein, mas encontra em Hiroshima mon amour um novo aspecto da montagem em direção a um cinema subjetivo. Esse conceito de cinema subjetivo, em alguns casos, aparece associado apenas à literatura moderna, uma vez que acreditavam não existir na história do cinema qualquer referência. Para José Lino Grünewald (Idem, p. 53), em Hiroshima mon amour as imagens não encontram correspondência na palavra e, a palavra por sua vez se apresenta "extemporânea" dando uma "noção de ausência" que é proporcionada pelo ritmo e pela forma recitada dos diálogos. Essa escolha de Alain Resnais, que em certo sentido destaca ainda mais o lirismo do texto de Marguerite Duras, ainda provoca um distanciamento do espectador em relação aos acontecimentos narrados na tela. Neste ponto, Ely Azeredo acredita que o espectador é convidado a refletir sobre o filme, abrindo possibilidades ilimitadas de interpretações. Por isso, a ideia também de que Hiroshima mon amour é um filme-revolução.

A ideia de filme-revolução, filme-ruptura, está pensada a partir da comparação com Cidadão Kane (1941, 1h59') de Orson Welles, filme símbolo de toda uma geração de críticos brasileiros. ${ }^{26}$ Esse foi um dos pontos de confluência que propiciou o diálogo entre a antiga e a novíssima geração de críticos que recebiam as novas mudanças estéticas da Nouvelle Vague com bons olhos. Exemplo dessa polêmica são as posições assumidas por Antônio Moniz Vianna, defensor inconteste de Cidadão Kane, e José Lino Grünewald, que vê no filme de Resnais o começo de uma nova era após Kane (cf. CASTRO in GRÜNEWALD, 2001, p. 13).

Cidadão Kane, de Orson Welles, filme exibido em 1941 no Brasil, causou um impacto comparável ao Hiroshima mon amour. Vinícius de Moraes, por exemplo, depois da exibição de Kane disse: "é uma renovação, uma ressurreição, é uma revolução completa na moderna cinematografia" (SOUZA, 1995, p. 107). Portanto, neste momento em que duas gerações de críticos de cinema $^{27}$ atuavam nos principais jornais e revistas

\footnotetext{
${ }^{26}$ O filme de Welles representou para a geração de críticos da década de 40 uma renovação no modelo narrativo imposto por Hollywood, reafirmando o cinema como arte, além de ter sido um dos centros da polêmica Cinema Mudo versus Sonoro do período. Sobre o assunto: SOUZA, 1995. 27 Em 1960, uma geração de jovens imberbes, como, por exemplo, Maurício Gomes Leite, José Lino Grünewald e José Haroldo Pereira despontaram como críticos de cinema e passaram a compartilhar os espaços dos jornais com a geração que os formou na atividade, como Antonio Moniz Vianna, Walter da Silveira, Paulo Emílio Salles Gomes. Essa diferença geracional foi responsável por um dos períodos mais férteis e vigorosos no campo das ideias da crítica de cinema no Brasil.
} 
especializadas, o debate em torno de Hiroshima mon amour perpassou essa ideia de qual dos filmes foi mais importante para a história do cinema.

A nova geração de críticos que atua em 1960 assiste ao filme de Welles em 1958, quando ele volta a ser exibido no Brasil, portanto dois anos antes da projeção de Hiroshima mon amour. O filme de Orson Welles confirma as expectativas da nova geração que conhecia suas qualidades a partir da fala entusiasmada da geração anterior. Mas, o que está no centro das discussões em torno de Kane e Hiroshima é a capacidade que ambos possuem em alterar e acrescentar novos elementos na linguagem cinematográfica, e nesse particular não há unanimidade nem na antiga nem na nova geração.

Passados 60 anos de sua primeira exibição, Hiroshima mon amour, exibido hoje, não provoca mais no espectador uma reação como a que ocorreu na década de 1960. Para além das questões históricas que envolveram o período, tanto do ponto de vista político quanto estético, Hiroshima mon amour é um marco do cinema moderno, alterando a concepção de cinema ao ser "uma nova forma das artes plásticas, da música e da literatura, ou que está na confluência de todas elas, ou que realiza a síntese de todas elas". ${ }^{28}$ As questões que suscitaram muitas críticas, o estranhamento da linguagem empregada por Alain Resnais, como o uso excessivo da palavra; uma montagem que respeita o fluxo do pensamento; a interferência da literatura no cinema; flashback sem uma função dramática, apenas para citar alguns pontos que gravitaram em torno de Hiroshima mon amour, hoje já foram completamente assimiladas pelo espectador. Como proclamou José Lino Grünewald em 1960, Hirsohima mon amour é "cinema de futuro". Por outro lado, Hiroshima mon amour é um filme que não fez escola, não encontramos no cinema atual filmes que se assemelham ao realizado por Alain Resnais. Na transcriação ${ }^{29}$ de uma obra literária escrita para tornar-se filme, Resnais imprime à palavra o mesmo peso de importância conferida às imagens para, juntas, ser a expressão de um tempo subjetivo, um universo de memórias e de atualizações de uma subjetividade.

Não se trata de situar e datar Hiroshima mon amour, nem muito menos de considerar que o tempo subjetivo seja uma linguagem exclusivamente alcançada por Alain Resnais. Mas, acreditamos que em Hiroshima mon amour encontramos os elementos necessários para ampliar o referencial do cinema como expressão poética.

\footnotetext{
${ }^{28}$ PEREIRA, José Haroldo. Hiroshima meu amor. Um poema audiovisual de arquitetura dialética. Encarte do DVD Hiroshima meu amor. Coleção Cinema Essencial. Aurora DVD.

29 "O termo transcriação exclui [...] processos de adaptações de obras literárias para cine ou tv. Não se trata de promover adequações entre o literário e o audiovisual, mas de se aceitar como princípio, os desafios de uma tarefa mais ambiciosa: trabalhar a expressão cinematográfica procurando-se uma equivalência estética a ser encontrada no texto escolhido" (PASSOS, 1997, p. 21).
} 


\section{Referências bibliográficas}

AZEREDO, Ely. "Depois de Hiroshima". Tribuna da Imprensa. Rio de Janeiro, 20 jul. 1960, p. 9.

BAECQUE, Antoine de; TESSON, Charles (org.). La Nouvelle Vague. III. Petite anthologie des Cahiers du Cinéma. Paris: Cahiers du Cinéma, 1999, p. 36-62.

BRUM, Alessandra. Hiroshima mon amour e a recepção da crítica no Brasil. São Paulo: Annablume, 2017.

LEITE, Maurício Gomes. "Hiroshima, mon amour": obra inavaliável abre caminho para a 'Stream of Consciousness' do cinema. Diário da Tarde. Belo Horizonte, 26 jan. 1960.

DUBREUILH, Simone. " Le Festival de Cannes. Hiroshima mon amour, le film le plus 'scandaleux' et le plus discute de tout le festival ». Libération, 9 mai. 1959.

GOMES, Paulo Emílio Salles. "A ideologia da crítica brasileira e o problema do diálogo cinematográfico". In: CALIL, Carlos Augusto; MACHADO, Maria Tereza (org.). Paulo Emílio: um intelectual na linha de frente. Rio de Janeiro; São Paulo: Embrafilme, 1986. p. 331-4.

GRÜNEWALD, José Lino. "Um filme é um filme”. O cinema de vanguarda dos anos 60. Org. de Ruy Castro. São Paulo: Companhia das letras, 2001.

MELLO E SOUZA, Cláudio. “Hiroshima, meu amor (I)". Diário Carioca. Rio de Janeiro, 23 jul. 1960.

MORAES, Tati. "Hiroshima, meu amor". França-filmes do Brasil. Rio de Janeiro, 1960.

PASSOS, Fernando. "Cinema e Literatura. Instrumentalização crítica e teorias da comunicação. Uma linha de pesquisa do mestrado em Multimeios". Cadernos de pós-graduação, ano 1, v. 1, n. 2, 1997, p. 21-9.

PERDIGÃO, Paulo. "I Convenção Nacional da Crítica de Cinematográfica". O Metropolitano. Rio de Janeiro, 27 nov. 1960.

PEREIRA, José Haroldo. "Hiroshima mon amour (IV)". Folha de Minas. Belo Horizonte, 21 out. 1960.

PEREIRA, José Haroldo. “Entrevista à Alessandra Brum”. Rio de Janeiro, 26 mar. 2008 (captação digital, 90 minutos).

SANZ, José. "Hiroshima mon amour (IV)". Jornal do Commercio. Rio de Janeiro, 2 set. 1960.

SILVEIRA, Walter. O Eterno e o Efêmero. Org. e notas de José Umberto Dias. Salvador: Oiti ed. e Produções culturais, v. 2, 2006.

SOUZA. José Inácio de Melo. A Carga da Brigada Ligeira: intelectuais e crítica cinematográfica, 1941-1945, v. 1, 1995, 262f. Tese (doutorado em Cinema). São Paulo: ECA /USP.

VIANNA, Antonio Moniz. “Um filme por dia”. Crítica de Choque (1946-73). Org. de Ruy Castro. São Paulo: Companhia das letras, 2004, p. 192. 
Recebido em 26 de maio de 2020

Aprovado em 27 de maio de 2020

Alessandra Brum é pesquisadora da Universidade Federal de Juiz de Fora e autora do livro Hiroshima mom amour e a recepção da crítica no Brasil (2014). Contato: alessandra.brum@ufjf.edu.br

ORCiD: https:// orcid.org/0000-0001-7346-9713 